\title{
Campaigning on the Internet: 2008 Presidential General Election Candidate Webpages
}

KOME - An International Journal of Pure Communication Inquiry Volume 4 Issue 2, p. 46-58.

(C) The Author(s) 2016

Reprints and Permission: kome@komejournal.com

Published by the Hungarian Communication

Studies Association

DOI: 10.17646/KOME.2016.24

\section{William L. Benoit ${ }^{1}$, Mark Glantz $^{2}$ and Leslie Rill ${ }^{3}$}

${ }^{1}$ Ohio University, USA

${ }^{2}$ St. Norbert's College, USA

${ }^{3}$ Intel Corporation, Hillsboro, OR, USA

\begin{abstract}
The Internet is becoming an increasingly important component of political campaigns. This study employed content analysis to apply Functional Theory and Issue Ownership Theory to Obama's and McCain's presidential candidate webpages in the 2008 campaign. Acclaims (92\%) were more common than attacks (98\%); defenses did not occur in this sample. Policy (82\%) was addressed more than character (18\%). When discussing policy, these candidates addressed future plans most frequently, followed by general goals and then past deeds; on character, candidates discussed ideals, then personal qualities, and then leadership ability. This study shows that as candidates use the Internet to reach voters, their webpages conform to theoretical expectations.
\end{abstract}

Keywords: 2008, president, candidate webpage, Functional Theory, functions, topics

\section{Introduction}

The 2008 American presidential campaign was unusual in that neither major party candidate was a sitting president or vice president; the last time this happened was in 1952. President George W. Bush was term-limited and his vice president, Dick Cheney, decided not to run for president. John McCain represented the incumbent (Republican) party, but neither major party candidate had experience in the Oval Office to serve as a basis for their campaigns. Indeed, politicians continue to find new and interesting ways to reach voters. The Internet has proven to be a tool that has several benefits for candidates and citizens alike. Candidate webpages cost

Acknowledgement: The authors acknowledge the support of the Department of Communication Chair Michael Kramer, the College of Arts \& Sciences Dean Michael O’Brien, Provost Brian Foster, and Chancellor Brady Deaton at the University of Missouri.

Address for Correspondence: William L. Benoit, email: benoitw[at]ohio.edu Article received on the 22th January, 2016. Article accepted on the 27th August, 2016.

Conflict of Interest: The authors declare no conflicts of interest. 
far less (than TV spots) to disseminate the candidate's message. Unlike debates, which occur on just a few days (usually four: three presidential and one vice presidential) during the general election campaign, webpages are available throughout the campaign and can be updated as necessary. Voters can access candidate webpages whenever it is convenient and they can choose what content they want to view (unlike TV spots, speeches, or debates). The ability to utilize this medium and the growing reliance of our society on the Internet for information make candidate webpages a viable campaigning tool. In 2008, Obama and McCain used this medium to share information regarding their candidacy and in an attempt to attract voters. In the 2016 Republican presidential primary, Donald Trump rewrote the "rules" of presidential campaigns. He routinely made remarks considered outrageous by many, which guaranteed continuous attention from the news media. Trump also relied far more on Twitter - and less on traditional media, such as television spots - than the other Republican candidates, and surprised many observers when he secured the Republican presidential nomination.

The purpose of this study is to provide a backdrop to help understand contemporary campaign webpages by analyzing the 2008 general election webpages of Obama and McCain according to the Functional Theory of Campaign Discourse (Benoit, 2007). This study will add to our understanding of presidential candidates' use of the Internet.

\section{Literature Review}

Research assessing Internet campaigning has increased tremendously in the last decade, examining a variety of levels of office. Recognizing the potential of the Internet, several scholars have investigated the Internet as a campaign medium; see, e.g., Bimber and Davis (2003), Chadwick (2006), Davis (1999), Gainous and Wagner (2011, 2014), Hendricks and Schill (2015), Katz, Barris, and Jain (2013), Klotz (2004), or Owen and Davis (2008). Studies on the Internet since 1996 have studied statewide elections, specifically congressional elections (Dulio, Goff, \& Thurber, 1999; Klotz, 1997, 1998; Klotz \& Broome, 1998) and state offices (Benoit, 2000). Considerable attention has also been given to Presidential elections (e.g., Benoit, 2007). This medium can duplicate other traditional media, providing, essentially, a multi-media smorgasbord of all other campaign messages (e.g., press releases, advertisements; biographies, issue positions; in print, audio, or video) was not always been touted as progress. In fact, when the Internet was first used for campaigns in 1996, some scholars were wary of the impact of this medium on the party system and the increased investment of large corporations (Margolis, Resnick, \& Tu, 1997). Websites during the 1996 campaign session were similar in most respects to other election messages (Klinenberg \& Perrin, 2000).

By 2000 candidate webpages have been used by more candidates and became larger (displaying more information) and more sophisticated. They began to include information on fund-raising and volunteering (Harbert, 2000; Schneider, 2000). For example, McCain in 2000 used the Internet to organize volunteers in different states (Tomlinson, 2003). Dimitrova (2015) observed that "by the time of the 2000 presidential election, candidate sites were widely accepted as a common campaign tool" (p. 15). Yet, despite these advances, and perhaps the perceived limited use of voters, websites were not regularly updated daily (Schneider, 2000), and were not consistent in the visual content that they provided (Wicks, Souley, \& Verser, 2003). The interactivity of the website also influenced the perceived learning and liking of a candidate (Ahem, Stromer-Galley, \& Neuman, 2000). Research has also found that perceptions of candidates changed after visiting websites (Hanson \& Benoit, 2005). Comparisons between Internet uses and non-Internet users, in terms of campaign gathering information also demonstrated differences in knowledge of issue stances (Johnson, Braima, \& Sothirajah, 1999). Benoit et al. (2013) applied Functional Theory to presidential candidates' webpages in the 
primary campaign. Acclaims $(85 \%)$ were more common than attacks $(15 \%)$; defenses were quite rare $(0.4 \%)$. These messages discussed policy more often than character ( $81 \%$ to $19 \%)$. More information on the nature of candidate web-pages would be useful to our understanding of this medium.

\section{Functional Theory}

This study used content analysis to investigate 2008 presidential candidate general election webpages. Functional Theory (Benoit, 2007, 2014a, 2014c) posits several axioms about political campaign messages. Each of these assumptions will be explained separately in this section.

\section{Axiom 1. Voting is a comparative act.}

Casting a vote requires that a citizen choose between two (or more, particularly in the primary phase) competing candidates. As such, vote choice it clearly entails a comparative judgment. Candidates are human beings so we cannot reasonably expect any candidate to be perfect; no matter how much one candidate or supporters revile an opponent, no candidate is utterly without redeeming qualities. Therefore, a citizen's vote choice represents a comparative judgment that one candidate appears to be preferable to the other candidate(s) on whatever basis is most important to each individual voter. Voters' candidate choices are best understood as based perceptions that citizens form of the candidates for office on the basis of their attitudes and the information that appears relevant to them when they consider their vote choice. This means that to win an election, a candidate must succeed at persuading enough voters to believe that he or she is a better candidate choice than others in the race.

\section{Axiom 2. Candidates must distinguish themselves from opponents.}

The assumption that voting is a comparative act leads directly to the second assumption of Functional Theory: Candidates must appear different from one another. Voters have no reason to prefer one candidate over another if the candidates appear to be the same. Candidates often adopt some similar policy positions (who would oppose, e.g., creating jobs or and protecting the U.S. from terrorism?). However, if the candidates agree on every issue (and project identical character), voters would have no reason to prefer one over another. Therefore, political candidates must articulate some distinctions between themselves and their opponent(s).

\section{Axiom 3. Political campaign messages allow candidates to distinguish themselves.}

It is necessary but not sufficient for candidates to possess some differences from their opponents; they must convey that information to voters. Campaign messages, such as television spots, debates, speeches, or candidate webpages are the means by which candidates reach voters to distinguish themselves from opponents. These message reach voters directly as well as indirectly via the press and other sources. 


\section{Axiom 4. Candidates establish preferability through acclaiming, attacking, and defending.}

Furthermore, it is necessary for candidates to express their differences with opponents, but again that is not in and of itself sufficient for obtaining votes. A candidate must appear to be different from his or her opponents in ways that voters favor. For instance, a candidate who declared that "I am the only candidate who will slash all government services" would surely stand apart from opponents - and might appeal to a few voters -- but be unlikely to persuade enough voters to win the election. So, a candidate must appear to be both different from and better than his or her opponent (and candidates, of course, can characterize the opponent as different and worse). Consistent with this assumption, Popkin (1994) explained that "Somehow, candidates manage to get a large proportion of the citizenry sorted into opposing camps, each of which is convinced that the positions and interests of the other side add up to a less desirable package of benefits" (p. 8). Only three kinds of statements or functions of discourse are capable of making a candidate appear preferable to opponents: acclaims (touting one's strengths), attacks (exposing an opponent's weaknesses), and defenses (responses to, or refutations of, attacks).

Political candidates and their campaign advisors also recognize the fundamental principle that campaign discourse performs multiple functions. For example, H. R. Haldeman offered this advice on the 1972 reelection campaign to President Richard M. Nixon: "Getting one of those 20 [percent] who is an undecided type to vote for you on the basis of your positive points is much less likely than getting them to vote against McGovern by scaring them to death about McGovern" (Popkin et al., 1976, p. 794n). Thus, Haldeman recognized that Nixon could win the election by praising himself - acclaiming Nixon's "positive points" - or by attacking his opponent - "scaring them to death about McGovern" - or both. Similarly, Vincent Breglio, part of Ronald Reagan's successful 1980 presidential campaign, acknowledged that "It has become vital in campaigns today that you not only present all the reasons why people ought to vote for you, but you also have an obligation to present the reasons why they should not vote for the opponent" (1987, p. 34). So, political campaign advisors, like political communication scholars, recognize that candidates must praise themselves and attack their opponents.

These three functions can be fruitfully understood as an informal form of cost-benefit analysis. Acclaims stress a candidate's benefits. Attacks reveal an opponent's costs. Defenses refute alleged costs. Consistent with this explanation, Kelley and Mirer (1974), using survey data from the 1952-1968 presidential elections, found that $82-87 \%$ of citizens voted for the candidate for whom they reported the largest number of reasons for liking that candidate and the smallest number of reasons for disliking that candidate (in other words, benefits and costs). This figure is not $100 \%$ because some citizens are single-issue voters. However, characterizing vote choice as similar to cost-benefit analysis does not mean that every voter takes a rational approach to voting, gathering, weighing, and integrating as much information as possible to guarantee that they make the most rational decision possible. As Zaller (1992) rightly observed, "citizens vary in their habitual attention to politics and hence in their exposure to political information and argumentation in the media" (p. 1). Nor do they engage in mathematical calculations (i.e., adding or averaging) to make a vote choice. The three functions work to make one candidate appear preferable to another.

Functional Theory predicts that these three functions are likely to occur with different frequencies. Acclaims, if persuasive (if accepted by the audience) can increase a candidate's apparent preferability and have no inherent drawbacks (although it does not mean that acclaims are always persuasive or, when they are persuasive, will influence all voters). This means that ordinarily acclaims should be the most common campaign discourse function. Attacks, in contrast, risk alienating some voters who detest mudslinging as noted above (Merritt, 1984; Stewart, 1975) so the risk of backlash may encourage candidates to moderate their attacks. 
Accordingly, Functional Theory expects attacks to be less common than acclaims. Note that Functional Theory does not declare that all candidates must acclaim more than they attack; only that candidates have a reason to do so. Defenses, if they are accepted by a voter, can help restore a candidate's lost preferability. However, defenses have three drawbacks: They are likely to take a candidate off-message (because attacks are likely to concern the target candidate's weaknesses), they risk informing or reminding voters of a potential weakness (a candidate must identify an attack to refute it), and defenses could create the impression that the candidate is reactive (defensive) rather than proactive. Thus, Functional Theory makes this prediction about the functions of political campaign discourse:

H1. Candidates will use acclaims more frequently than attacks and attacks more often than defenses.

\section{Axiom 5. Campaign discourse occurs on two topics: policy and character.}

Functional Theory posits that political discourse can occur on two broad topics: policy (issues) and character (image). Rountree (1995), for example, contrasts actus (behavior, action) and status (nature) in political discourse. Policy utterances concern governmental action (past, current, or future) and problems amenable to governmental action; in contrast, character utterances address characteristics, traits, abilities, or attributes of the candidates. This means that political candidates attempt to persuade voters of their preferability on policy and character. Consistent with this assumption, Pomper (1975) noted that many voters "change their partisan choice from one election to the next, and these changes are most closely related to their positions on the issues and their assessment of the abilities of the candidates" (p. 10; Functional Theory also subdivides policy and character utterances into finer categories, as discussed later).

Functional Theory predicts that, particularly in presidential campaigns, policy will be a more frequent topic of campaign messages than character. We elect presidents to run our government, or to implement policy. Although some voters believe that they elect positive role models - and surely we all hope our elected leaders are positive role models - the primary duty of our elected officials is to administer policy. Hofstetter (1976) explains that "issue preferences are key elements in the preferences of most, if not all, voters" (p. 77). Public opinion poll data from every campaign from 1976 to 2004 establish that the majority of voters believe that policy is more important than character in their vote for president (Benoit, 2003). Character does matter, of course. We must trust candidates to work to achieve their campaign promises, and we must trust them to implement suitable policies in unexpected situations on which they did not take policy stands during the campaign. Still, because most voters consider policy to be more important than character, Functional Theory holds that candidates are likely to respond to these preferences so that policy will be discussed more frequently in presidential campaign messages than character. This leads to the second prediction:

H2. Policy comments will be more frequent than character comments in presidential campaign discourse.

Again, Functional Theory does not declare that all candidates must address policy more than character; it explains that they have reasons to emphasize policy.

Axiom 6. A candidate must win a majority (or a plurality) of the votes cast in an election. 
In the United States presidential elections are decided by the Electoral College rather than the popular vote. This is important because candidates need not persuade everyone to vote for him or her. This is a good thing because so many issues are controversial, so it is impossible to persuade every voter that your issue stands are the proper ones. A candidate only needs to persuade enough of those who are voting in enough states to win 270 electoral votes. This encourages presidential candidates to campaign more vigorously in some states than others. The 2000 presidential election underscored the importance of the electoral vote. As voting returns came in on Tuesday night Florida was "given" to Gore, taken back, given to Bush, and then taken back again. Then the recounts in Florida made the nation wait for the winner to be determined as the outcome of the election hinged on whether Florida's 25 electoral votes belonged to Bush or Gore. The U.S. Supreme Court (in a 5 to 4 vote) ultimately decided to halt recounts in Florida, giving the Electoral College majority to Bush. Eventually we learned that $\mathrm{Al}$ Gore won the popular balloting by a margin of half a million votes, but because Bush won Florida by 537 votes, he won all of its Electoral College votes and the presidency (New York Times, 2001). Thus, a candidate only needs to win a majority of votes in enough states to amass 270 electoral votes to win the presidency.

Research on the 2000 general election campaign webpages found that candidates used this medium to acclaim more than to attack (98\% to 2\%) and used no defenses (Benoit et al., 2003). The 2004 candidate general webpages (Benoit et al., 2007) also acclaimed more than they attacked $(87 \%, 13 \%)$ and offered no defenses. The 2008 Democratic and Republican presidential primary webpages also stressed acclaims $(85 \%)$ over attacks $(15 \%)$ with virtually no defenses (0.4\%; Benoit et al. 2013). Acceptance addresses (Benoit, 2014b), TV spots (Benoit \& Glantz, 2012), and debates (Benoit \& Rill, 2013) showed the same basic pattern of more acclaims than attacks and few defenses. The predicted ordering of functions occurred in each message form in these campaigns. However, we do not yet have data on the functions of general election webpages of 2008.

The candidate general election campaign webpages created by candidates in 2000 discussed policy $(90 \%)$ more than character (10\%; Benoit et al., 2004). In 2004, candidates again emphasized policy more than character in general election webpages (75\% to $25 \%$; Benoit et al. 2007). Candidate primary webpages in 2008 once again stressed policy (81\%) over character (19\%; Benoit et al 2013). Acceptance addresses (Benoit, 2014b), TV spots (Benoit \& Rill, 2013), and debates (Benoit \& Glantz, 2012) in the 2008 general election talked more about policy. Every one of these message forms in these campaigns privileged policy over character. Again, we have no data from 2008 general election webpages on the topics of these messages. Functional Theory divides policy statements into three forms: past deeds (record in office), future plans (means to improve the state of affairs), and general goals (ends sought in public policy). It also divides character into three forms: personal qualities (character traits), leadership ability (experience in office), and ideals (principles and values). Examples of acclaims and attacks on the three forms of policy and of character are available in several sources (e.g., Benoit, 2007; Benoit et al., 2005; Benoit et al., 2007; Benoit et al., 2013). Our research question investigates the distribution of these utterances:

RQ1. What is the relative frequency of the three forms of policy and three forms of character?

In 2000, Bush and Gore used their general election webpages to discuss past deeds (64\%), future plans (19\%), and general goals (17\%; Benoit et al., 2003). In 2004 (Benoit et al., 2007), the general candidate webpages discussed past deeds (32\%), future plans (19\%), and general goals (49\%). Benoit et al. (2013) found that the primary webpages in 2008 discussed past deeds 
(33\%), future plans (21\%), and general goals (46\%). Acceptances from 2008 (Benoit, 2014) talked about past deeds, future plans, and general goals $(32 \%, 5 \%, 63 \%)$. The television spots in that campaign also stressed general goals $(51 \%)$ over past deeds $(35 \%)$ or future plans $(14 \%)$. The general election debates of 2008 had roughly similar proportions (31\% past deeds, $15 \%$ future plans, 54\% general goals. Most of these message forms stressed general goals (only the 2000 general election webpages relied most heavily on past deeds). We do not yet know about the allocation of the forms of policy in general election webpages from 2008.

During the 2000 general campaign (Benoit et al., 2003), candidate webpages discussed personal qualities (24\%), leadership ability (11\%), and ideals (64\%). In the 2004 general election, candidates discussed personal qualities (33\%), leadership ability (36\%), and ideals (31\%) on their webpages (Benoit et al., 2007). Acceptance addresses (Benoit, 2014b) discussed the forms of character in these proportions: personal qualities $44 \%$, leadership ability $14 \%$, and ideals $41 \%$. Television advertising in the 2008 general election campaign also stressed personal qualities $(60 \%)$ over leadership ability $(20 \%)$ or ideals $(20 \%$; Benoit \& Glantz, 2012). The debates that year (Benoit \& Rill, 2013) also emphasized personal qualities (54\%), leadership ability (26\%), and ideals (20\%). No clear pattern emerged for allocation of forms of policy in general campaign webpages, but in the general election all three message forms emphasized personal qualities. Again, we do not know how the forms of character were allocated in 2008 general webpages.

Functional theory anticipates that it is easier to acclaim than to attack general goals (who opposes creating jobs?) or ideals (who can oppose freedom)? This leads to two additional predictions:

H3. The 2008 general election webpages will acclaim more than they attack on general goals.

This pattern held in general election webpages from Bush and Gore in 2000 (99\% to 1\%; Benoit et al., 2003) and in webpages from Bush and Kerry in 2004 (95\%, 5\%; Benoit et al., 2007). It was also confirmed in 2008 acceptances (Benoit, 2014b), TV spots (Benoit \& Glantz, 2012), and debates (Benoit \& Rill, 2013). This prediction was supported consistently in these studies. We have yet to see if this pattern holds in 2008 general election candidate webpages.

H4. The 2008 general election webpages will acclaim more than they attack on ideals.

In general election candidate webpages in 2000, Bush and Gore followed this pattern (99\% to 1\%; Benoit et al., 2003) as did Bush and Kerry in 2004 (95\%, 5\%; Benoit et al., 2007) the candidates acclaimed more than they attacked on ideals. This prediction was confirmed in Acceptances (Benoit, 2014b), TV spots (Benoit \& Glantz, 2012), and debates (Benoit \& Rill, 2013). We do not know if this prediction would be upheld in 2008 general webpages. Testing these hypotheses and answering these research questions will add to our understanding of political candidates' use of webpages.

\section{Methods}

Transcripts of candidate webpages (homepage, issues sections, and biographies) were downloaded from the Internet just before election day in 2008 and then unitized into themes, or utterances that address a coherent idea. Berelson (1952) defined a theme as "an assertion about a subject" (p. 18). Similarly, Holsti (1969) stipulated that a theme is "a single assertion about some subject" (p. 116). Basically, a theme in this study is a claim or an argument 
(argument 1; see O'Keefe, 1977) about the candidates. Because rhetoric is enthymematic (i.e. audiences can "fill in" arguments that are sketched in discourse), themes vary in length from a phrase to several sentences. For instance, if a candidate said, "I will protect Medicare, reduce crime, and create jobs," that sentence would be considered to have three themes because it has three subjects: Medicare, crime, and jobs. On the other hand, a single theme can spread across several sentences. For example, a candidate could declare that "Jobs are important to the economy. I promise to increase job creation. We cannot have too many jobs." A single theme (a general goal of job creation) spans these three sentences.

First, each theme was classified by function (as an acclaim, attack, or defense) according to these rules:

- Acclaims are themes that portray the candidate favorably.

- Attacks are themes that portray the opposing candidate unfavorably.

- Defenses are themes that refute attacks against the candidate.

- Only utterances that performed the functions of acclaiming, attacking, or defending (which were in fact virtually all of themes in these webpages) were analyzed in this research.

Second, each theme was classified by topic, as addressing policy or character, according to these rules:

- Policy themes concern governmental action (past, current, or future) and problems amenable to governmental action.

- Character themes concern the characteristics, traits, abilities, or attributes of the candidates.

Third, each policy theme was coded into one of the three forms of policy (past deeds, future plans, general goals); each character theme was classified into one of the three forms of character (personal qualities, leadership ability, ideals).

Inter-coder reliabilities for these variables were good. Multiple coders analyzed these transcripts: Cohen's kappa (1960) for function ranged from .91-.94, for topic it ranged from .84-.87, for form of policy it varied from .88-.91, and for form of character it ranged from .85.89. Landis and Koch (1977) explain that values of kappa between 0.81 and 1.0 reflect "almost perfect" inter-coder reliabilities (p. 165). These values give confidence in the coding of these messages.

\section{Results}

\section{Functions of 2008 Candidate General Election Webpages}

The first hypothesis addressed the functions of the 2008 presidential candidate webpages in the general election. Overall, the candidates were extremely positive in their messages, with $92 \%$ percent of statements being acclaims and $8 \%$ attacks. No defenses occurred on these webpages. A chi-square goodness of fit test confirms that acclaims did not occur with the same frequency as attacks $(d f=1,1162.78 p<.0001)$; defenses were too infrequent to include in the analysis. These data are reported in Table 1. 
Table 1. Functions of 2008 Candidate General Election Webpages

\begin{tabular}{|c|c|c|c|}
\hline & Acclaims & Attacks & Defenses \\
\hline Obama & $634(92 \%)$ & $58(8 \%)$ & 0 \\
\hline McCain & $902(92 \%)$ & $82(8 \%)$ & 0 \\
\hline Total & $1536(92 \%)$ & $151(8 \%)$ & 0 \\
\hline
\end{tabular}

\section{Topics of 2008 General Election Candidate Webpages}

Hypothesis two addressed the topics of these Internet sites. Candidates devoted the majority of their statements to policy statements $(82 \%)$ and fewer comments to character (18\%). A chisquare goodness of fit test confirmed that this difference was significant $(d f=1,698.52, p<$ .0001). See Table 2 for these data.

Table 2. Topics of 2008 General Election Candidate Webpages

\begin{tabular}{|c|c|c|}
\hline & Policy & Character \\
\hline Obama & $640(92 \%)$ & $52(8 \%)$ \\
\hline McCain & $739(75 \%)$ & $245(25 \%)$ \\
\hline Total & $1379(82 \%)$ & $297(18 \%)$ \\
\hline
\end{tabular}

Forms of Policy and Character in 2008 General Election Candidate Webpages

The research question investigated the relative frequency of the three forms of policy and of the three forms of character. Obama and McCain discussed past deeds (22\%) future plans $(47 \%)$, and general goals $(31 \%)$. These candidates' webpages discussed personal qualities $(38 \%)$, leadership ability (17\%), and ideals (44\%). These data are reported in Tables 3 and 4. General goals and personal qualities were discussed frequently here, but not as much as in other cases reviewed earlier.

Table 3. Forms of Policy in 2008 Candidate General Election Webpages

\begin{tabular}{|c|c|c|c|c|c|c|}
\hline & \multicolumn{2}{|c|}{ Past Deeds } & \multicolumn{2}{c|}{ Future Plans } & \multicolumn{2}{c|}{ General Goals } \\
\cline { 2 - 7 } & Acclaims & Attacks & Acclaims & Attacks & Acclaims & Attacks \\
\hline Obama & 62 & 30 & 513 & 21 & 13 & 0 \\
\hline McCain & 171 & 43 & 89 & 6 & 409 & 21 \\
\hline Total & 233 & 73 & 602 & 27 & 422 & 21 \\
\hline & \multicolumn{2}{|c|}{$308(22 \%)$} & \multicolumn{2}{c|}{$629(47 \%)$} & \multicolumn{2}{c|}{$442(31 \%)$} \\
\hline
\end{tabular}


Table 4. Forms of Character in 2008 Candidate General Election Webpages

\begin{tabular}{|c|c|c|c|c|c|c|}
\hline & \multicolumn{2}{|c|}{ Personal Qualities } & \multicolumn{2}{c|}{ Leadership Ability } & \multicolumn{2}{c|}{ Ideals } \\
\cline { 2 - 7 } & Acclaims & Attacks & Acclaims & Attacks & Acclaims & Attacks \\
\hline Obama & 2 & 0 & 0 & 24 & 19 & 2 \\
\hline McCain & 104 & 6 & 6 & 21 & 108 & 1 \\
\hline Total & 106 & 5 & 6 & 45 & 127 & 3 \\
\hline & \multicolumn{2}{|c|}{$112(38 \%)$} & \multicolumn{2}{|c|}{$51(17 \%)$} & \multicolumn{2}{c|}{$130(49 \%)$} \\
\hline
\end{tabular}

\section{Functions of General Goals and Ideals}

$\mathrm{H} 3$ predicted that candidates would acclaim more than they attacked when discussing general goals. This hypothesis was confirmed in these data (95\% acclaims, 5\% attacks). A chi-square goodness of fit test confirmed that this difference was significant $(d f=1,362.98, p<.0001)$. The fourth hypothesis predicted that the functions of ideals would show a similar pattern, which they did: $98 \%$ of ideals were acclaims while $2 \%$ were attacks. A chi-square goodness of fit test confirmed that this difference was significant $(d f=1,118.28, p<.0001)$.

\section{Discussion}

The purpose of this investigation was to assess the content of 2008 Presidential general election candidate webpages by Obama and McCain using Functional Theory. Previous research on candidate webpages has demonstrate the potential to influence voters on variable such as learning (Johnson, et al., 1999), perceptions of candidates (Hansen, 2002), and candidate liking (Ahem et al., 2008). The results of the analysis presented here - more acclaims than attacks and few defenses; more policy than character; more acclaims than attacks on general goals and on ideals - are consistent with past research on general election webpages from 2000 and 2004: Previous analyses of candidate webpage content found that candidates focus on policy more than character and are more positive in their utterances (Benoit et. al., 2003; 2007). These patterns occurred in other messages forms in 2008 (acceptance addresses: Benoit, 2014b; TV spots: Benoit \& Glantz, 2012, and debates: Benoit \& Rill, 2013).

Results of this analysis indicate that both parties were extremely positive in statements on the Internet and focused predominantly on policy. Specifically, both Democrats and Republicans were over $80 \%$ positive in their statements. Of the forms of policy, both parties focused more on past deeds. Candidates of both parties also attacked the status quo more often than other candidates or the current administration. This research provides evidence that the predictions of Functional Theory are pertinent to candidate messages on the Internet. In 2016, Donald Trump is widely perceived as a particularly negative candidate. It would be very interesting to see whether content analysis supports this perception.

\section{Conclusion}

This study extended our understanding of the content of presidential candidate webpages to the 2008 general election. Results confirm the predictions of Functional Theory: acclaims were more common than attacks and defenses were rare. Acclaims were more common - and attacks less common - in webpages than acceptance addresses (Benoit, 2014b), television spots (Benoit \& Glantz, 2012), or debates (Benoit \& Rill, 2013) from the 2008 campaign. The 
candidate webpages stressed policy even more (and character less) than acceptances (Benoit, 2014b), TV spots (Benoit \& Glantz, 2012), or debates (Benoit \& Rill, 2013) from the same campaign. It would be helpful to extend this line of research to include presidential candidate webpages from 2012 and 2016 as well as to extend it to other media, such as Twitter or Facebook.

\section{References}

Ahem, R. K., Stromer-Galley, J., \& Neuman, R. W. (2000). When voters can interact and compare candidates online: Experimentally investigating political web effects. Paper presented at the International Communication Association, Acapulco, Mexico.

Benoit, W. L. (2000). A functional analysis of political advertising across media, 1998. Communication Studies, 51, 274-295. CrossRef

Benoit, W. L. (2003). Topic of presidential campaign discourse and election outcome. Western Journal of Communication, 67, 97-112.

Benoit, W. L. (2007). Communication in political campaigns. New York: Peter Lang.

Benoit, W. L. (2014a). A functional analysis of presidential television advertisements ( $2^{\text {nd }}$ ed.). Lanham, MD: Lexington Books.

Benoit, W. L. (2014b). A Functional Analysis of 2008 and 2012 presidential nomination acceptance addresses, Speaker \& Gavel, 51, 50-59.

Benoit, W. L. (2014c). Political election debates: Informing voters about policy and character. Lanham, MD: Lexington Books.

Benoit, W. L., \& Glantz, M. (2012). A Functional analysis of 2008 general election presidential TV spots. Speaker \& Gavel, 49, 1-19.

Benoit, W. L., Henson, J., Davis, C., Glantz, M., Phillips, A., \& Rill, L. (2013). Stumping on the Internet: 2008 presidential primary candidate campaign webpages. Human Communication, 16, 1-12.

Benoit, W. L., McHale, J. P, Hansen, G. J., Pier, P. M., \& McGuire, J. P. (2003). Campaign 2000: A functional analysis of presidential campaign discourse. Lanham, MD: Rowman \& Littlefield.

Benoit, W. L., \& Rill, L. (2013). A Functional analysis of 2008 general election debates. Argumentation and Advocacy, 50, 34-46.

Benoit, W. L., Stein, K. A., McHale, J. P.,Chattopadhyay, S., Verser, R., Price, S. (2007). Bush versus Kerry: A functional analysis of campaign 2004. New York: Peter Lang.

Berelson, B. (1952). Content analysis for the social sciences and humanities. Reading, MA: Addison-Wesley.

Bimber, B. A., \& Davis, R. (2003). Campaigning online: The Internet in U.S. elections. New York: Oxford University Press.

Breglio, V. (1987). Polling in campaigns. In L. P. Devlin (Ed.), Political persuasion in presidential campaigns (pp. 24-34). New Brunswick, NJ: Transaction Books.

Chadwick, A. (2006). Internet politics: States, citizens, and new communication technologies. New York: Oxford University Press.

Cohen, J. (1960). A coefficient of agreement for nominal scales. Educational and Psychological Measurement, 20, 37-46. CrossRef

Davis, R. (1999). The web of politics: The Internet's impact on the American political system New York: Oxford University Press.

Dimitrova, D. V. (2015). The evolution of digital media use in election campaigns. In J. R. Hencricks \& D. Shill (Eds.), Presidential campaigning and social media (pp. 15-27). New York: Oxford University Press. 
Dulio, D. A., Goff, D. L., \& Thurber, J. A. (1999). Untangled web: Internet use during the 1998 election. PS: Political Science and Politics, 32, 53-58. CrossRef

Gainous, J., \& Wagner, K. M. (2011). Rebooting American politics: The Internet revolution. Lanham, MD: Rowman \& Littlefield.

Gainous, J., \& Wagner, K. M. (2014). Tweeting to power: The social media revolution in American politics. Oxford: Oxford University Press.

Hansen, G. J., \& Benoit, W. L. (2005). Presidential campaigning on the web: The influence of candidate World Wide Web sites in the 2000 general election. Southern Communication Journal, 70, 219-229. CrossRef

Hendricks, J. A., \& Schill, D. (2015). Presidential campaigning and social media: An analysis of the 2012 campaign. New York: Oxford University Press.

Hofstetter, C. R. (1976). Bias in the news: Network television coverage of the 1972 election campaign. Columbus, $\mathrm{OH}$ : Ohio State University Press.

Holsti, O. (1969. Content analysis in communication research. New York: Free Press.

Johnson, J. T., Braima, M. A. M., \& Sothirajah, J. (1999). Doing the traditional media sidestep: Comparing the effects of the Internet and other nontraditional media with traditional media in the 1996 presidential campaign. Journalism and Mass Communication Quarterly, 76(1), 99-123. CrossRef

Katz, J. E., Barris, M., \& Jain, A. (2013). The social media president: Barack Obama and the politics of digital engagement. New York: Palgrave.

Kelley, S., \& Mirer, T. W. (1974). The simple act of voting. American Political Science Review, 68, 572-591. CrossRef

Klinenberg, E., \& Perrin, A. (2000). Symbolic politics in the information age: The 1996 Republican presidential campaigns in cyberspace. Information, Communication, and Society, 3, 17-38. CrossRef

Klotz, R. (1997). Positive spin: Senate campaigning on the Web. PS: Political Science and Politics, 30, 482-486. CrossRef

Klotz, R. (1998). Virtual criticism: Negative advertising on the Internet in the 1996 Senate races. Political Communication, 15, 347-365. CrossRef

Klotz, R. J. (2004). The politics of Internet communication. Lanham, MD: Rowman \& Littlefield.

Klotz. R., \& Broome, A. (1998). Discussion of women's issues in the 1996 Internet campaign. Women and Politics, 19(4), 78-96. CrossRef

Landis, J. R., \& Koch, G. G. (1977). The measurement of observer agreement for categorical data. Biometrica, 33, 159-174. CrossRef

Margolis, M., Resnick, D., \& Tu, C. (1997). Campaigning on the Internet: Parties and candidates on the World Wide Web in the 1996 primary season. The International Journal of Press/Politics, 2(1), 59-78. CrossRef

Merritt, S. (1984). Negative political advertising: Some empirical findings. Journal of Advertising, 13, 27-38. CrossRef

O'Keefe, D. J. (1977). Two concepts of argument. Journal of the American Forensic Association, 13, 121-128.

Owen, D., \& Davis, R. (2008). Presidential communication in the Internet era. Presidential Studies Quarterly, 38, 658-673. CrossRef

Pomper, G. M. (1975). Voters' choice: Varieties of American electoral behavior. New York: Dodd, Mead, \& Company.

Popkin, S. L., Gorman, J., Smith, J., \& Phillips, C. (1976). Comment: toward an investment theory of voting behavior: What have you done for me lately? American Political Science Review, 70, 779-805. 
Rountree, J. C. (1995). The president as God, The recession as evil: Actus, status, and the president's rhetorical bind in the 1992 election. Quarterly Journal of Speech, 81, 325352. CrossRef

Schneider, S. M. (2000). The 2000 presidential primary candidates: The view from the web. Paper presented at the International Communication Association, Acapulco, Mexico.

Stewart, C. J. (1975). Voter perception of mud-slinging in political communication. Central States Speech Journal, 26, 279-286. CrossRef

Tomlinson, J. E. (2003). Organizing an online campaign: The legacy of McCain2000.com. In L. L. Kaid, J. C. Tedesco, D. G. Bystrom, and M. S. McKinney (eds.), The millennium election: Communication in the 2000 campaign. New York: Rowman \& Littlefield Publishers, Inc.

Wicks, R. H., \& Souley, B. (2003). Going negative: Candidate usage of Internet web sites during the 2000 presidential campaign. Journalism \& Mass Communication Quarterly, 80, 128-144. CrossRef

Wicks, R. H., Souley, B., \& Verser, R. M. (2003). Differences and similarities in use of campaign websites during the 2000 Presidential election. In L. L. Kaid, J. C. Tedesco, D. G. Bystrom, and M. S. McKinney (eds.), The Millennium Election: Communication in the 2000 Campaign. New York: Rowman \& Littlefield Publishers, Inc.

Zaller, J. R. (1992). The nature and origins of mass opinion. New York, NY: Cambridge University Press. 